\title{
PENGARUH MEDIA PERMAINAN ULAR TANGGA TERHADAP MOTIVASI BELAJAR PADA PELAJARAN MATEMATIKA KELAS II SD KEMALA BHAYANGKARI 1 SURABAYA
}

\author{
Nur Afifah $^{1}$, Sri Hartatik ${ }^{2}$ \\ ${ }^{1,2}$ Universitas Nahdlatul Ulama Surabaya \\ nurafifah20061997@ gmail.com ${ }^{1}$, titax@unusa.ac,id ${ }^{2}$
}

\begin{abstract}
ABSTRAK
Penelitian ini bertujuan untuk mengetahui pengaruh media permainan ular tangga terhadap motivasi belajar siswa pada mata pelajaran matematika. Jenis penelitian ini adalah kuantitatif dengan metode eksperimen. Desain penelitian menggunakan pre-experimental designs dengan bentuk One-Group Pretest-Posttest Design. Subjek penelitian ini adalah siswa kelas II SD Kemala Bhayangkari 1 Surabaya. Teknik Pengumpulan data menggunakan angket yang diberikan sebelum dan sesudah diberi perlakuan teknik analisis data menggunakan analisis kuantitatif deskriptif dan uji Wilcoxon Signed Rank Test. Hasil penelitian menunjukkan: (1) motivasi belajar siswa sebelum diterapkan media permainan ular tangga sebesar 53,09\% dengan kriteria kurang, (2) motivasi belajar siswa sesudah diterapkan media permainan ular tangga sebesar $75 \%$ dengan kriteria baik, (3) hasil pengolahan data dengan menggunakan uji Wilcoxon Signed Rank Test menunjukkan nilai Asymp. Sig 0,000 < 0,05 maka dapat diyatakan bahwa Ho ditolak, maka dapat disimpulkan bahwa ada pengaruh penggunaan media permainan ular tangga terhadap motivasi belajar siswa.
\end{abstract}

Kata kunci: belajar siswa, media permainan ular tangga, motivasi

\begin{abstract}
This study aims to determine the effect of snake ladder game media on student learning motivation on math subjects. This type of research is quantitative with the experimental method. The research design uses pre-experimental designs in the form of One-Group Pretest-Posttest design. The subject of this study was the second grade students of SD Kemala Bhayangkari 1 Surabaya. Data collection techniques using questionnaires were given before and after treatment. The data analysis technique uses the Wilcoxon Signed Rank Test and descriptive quantitative analysis. The results of the study show: 1) Student motivation before applied to the snake ladder game media was $53.09 \%$ with less criteria, 2) Student learning motivation after being applied to the snake ladder game media was $75 \%$ with good criteria, 3) The results of processing data using the Wilcoxon Signed Rank Test show the value of Asymp. Sig 0,000<0,05, it can be stated that Ho is rejected. Then it can be concluded that there is an influence of the use of snake ladder game media on student learning motivation.
\end{abstract}

Keywords: student learning, game snakes ladders media, motivation

\section{PENDAHULUAN}

Matematika merupakan cabang ilmu pengetahuan yang erat kaitannya dalam kehidupan sehari-hari, yang berisi penalaran logis dan masalah-masalah yang berhubungan dengan bilangan (Zulfa, 2016). Oleh karena itu, matematika 


\section{Nur Afifah, Sri Hartatik}

memiliki kedudukan yang sangat penting dalam pendidikan dan perlu diajarkan di Sekolah Dasar untuk melatih siswadalam berpikir kritis, logis, dan sistematis.Banyak siswa yang mengangap bahwa matematika sebagai mata pelajaran yang paling sulit untuk dipelajari dan dipahami, tetapi semua siswa harus mempelajarinya karena matematika merupakan sarana untuk memecahkan masalah dalam kehidupan sehari-hari.

Berdasarkan hasil observasi pada hari Senin, 28 Oktober 2018 di kelas II SD Kemala Bhayangkari 1 Surabaya menunjukkan bahwa:siswa rendah dalam pelajaran matematika, dan motivasi belajar siswa masih rendah terutama pada mata pelajaran matematika, terlihat pada saat pembelajaran di kelas siswa kurang antusias, siswa mudah putus asa ketika mengerjakan soal apalagi soal perkalian dan pembagian. Lemahnya siswa dalam materi perkalian dan pembagian dikarenakan dalam proses pembelajaran matematika kurang menarik, kurangnya variasi metode dalam proses pembelajaran, disisi lain perhatian dan motivasi orang tua terhadap anak dalam belajar di rumah juga masih kurang. Hal ini berakibat pada rendahnya minat siswa dalam mengikuti pembelajaran matematika dan motivasi belajar siswa menjadi rendah.

Motivasi belajar merupakan suatu perasaan yang muncul dalam diri yang ditandai dengan perasaan senang dan bergairah saat melakukan aktivitas belajar (Sumantri, 2015), sedangkan menurut (Iskandar, 2009) motivasi belajar adalah daya penggerak dari dalam individu untuk melakukan kegiatan belajar untuk menambah pengetahuan dan ketrampilan serta pengalaman. Jadi motivasi belajar merupakan suatu dorongan baik dari dalam diri individu maupun dari luar individu untuk menumbuhkan semangat siswadalam melakukan kegiatan belajar agar lebih giat dalam belajar untuk memperoleh prestasi yang lebih baik lagi. Motivasi belajar dapat dibagi menjadi dua, yaitu motivasi intrinsik dan motivasi ekstrinsik, motivasi intrinsik adalah motivasi yang timbul dari dalam diri individu, contohnya anak yang senang membaca, tidak perlu ada yang menyuruhnya membaca karena ia sudah rajin mencari buku untuk dibacanya.Sedangkan motivasi ekstrinsik adalah motivasi yang muncul dari luar individu, contohnya mendapat semangat dari orang lain. Salah satucara untuk menumbuhkan motivasi belajar siswayakni dengan menggunakan media pembelajaran, sejalan dengan 


\section{Pengaruh Media Permainan Ular Tangga Terhadap Motivasi Belajar pada Pelajaran Matematika}

Kelas II SD Kemala Bhayangkari 1 Surabaya

pendapat Hamalik (dalam Arsyad, 2013) bahwa pemakaian media pembelajaran dalam proses belajar mengajar dapat membangkitkan keinginan, minat, dan motivasi belajar serta rangsangan kegiatan belajar. Selain itu media yang dikemas dengan menarik dapat menarik perhatian siswadan menumbuhkan semangat belajar dalam diri siswa itu sendiri. Media pembelajaran merupakan alat dan bahan yang digunakan untuk mengefektifkan dan mengefisienkan proses pembelajaran untuk mencapai tujuan pembelajaran (Satrianawati, 2018). Melalui penggunaan media pembelajaran yang menarik serta bimbingan guru diharapkan dapat meningkatkan motivasi belajar siswa.

Proses pembelajaran yang baik itu seharusnya dapat membangkitkan kegiatan belajar yan efektif, bermakna dan menyenangkan. Menurut Ismail (2006), "Belajar sambil bermain adalah salah satu upaya dalam menyampaikan materi kepada anak dengan cara bermain atau dengan cara menyenangkan, sehingga tanpa disadari anak memperoleh pengetahuan dan pengalaman dari proses belajar yang mudah". Dengan demikian belajar sambil bermain merupakan salah satu cara yang efektif dan tidak membosankan dalam proses pembelajaran. Mengingat bahwa bermain merupakan dunia anak-anak, salah satu media yang dapat digunakan dalam pembelajaran matematika adalah permainan ular tangga.

Media permainan ular tangga merupakan media yang disertai dengan bermain, sehingga cocok dengan karakteristik siswa yang suka bermain. Media permainan ular tangga adalah suatu media yang menyerupai permainan ular tangga, namun setiap petak berisi soal dimana setiap pemain harus melewati dan menjawab soal tersebut. Permainan ular tangga bertujuan agar siswa senang mengikuti pembelajaran, sehingga dapat termotivasi dalam belajar. Melalui media permainan ular tangga ini diharapkan siswa akan lebih mudah menguasai materi dan dapat meningkatkan motivasi belajar siswa.

\section{METODE PENELITIAN}

Penelitian ini merupakan penelitian kuantitatif dengan metode eksperimen. Desain penelitian menggunakan pre-experimental designs dengan bentuk One- 
Group Pretest-Posttest Design. Dalam desain ini, membandingkan motivasi awal siswa antara motivasi akhir siswa setelah diberi pelakuan.

Tempat pelaksanaan penelitian ini di SD Kemala Bhayangkari 1 Surabaya dengan menggunakan kelas II sebagai sasaran penelitian untuk diberikan perlakuan dengan menggunakan media permainan ular tangga. Waktu pelaksanaan penelitian ini adalah pada bulan Maret tahun ajaran 2018-2019.

Populasi dalam penelitian ini adalah siswa kelas II SD Kemala Bhayangkari 1 Surabaya. Teknik penentuan sampel yang digunakan adalah non probability sampling, yaitu teknik sampling jenuh. Sampling jenuh adalah dimana semua anggota popuasi dijadikan sampel karena jumlah populasi relatif kecil, hanya 21 orang.

Instrumen yang digunakan dalam penelitian ini berupa angket yang dibuat dalam bentuk butir-butir peryataan yang dibuat sesuai dengan indikator yang akan diukur, sehingga dapat terarahkan oleh tujuan masalah dan hipotesis penelitian. Angket digunakan untuk mengetahui motivasi siswa terhadap pembelajaran matematika. Angket yang digunakan berbentuk ceklist dengan menggunakan skala Guttman. Teknik pengumpulan data yang digunakan adalah angket. Teknik analisis yang dilakukan adalah menggunakan Wilcoxon Signed Rank Test dan analisis kuantitatif deskriptif. Menurut Arikunto (2008) menyatakan bahwa pembagian kategori motivasi belajar diberikan pada Tabel 1.

Tabel 1. Kategori Motivasi Belajar Siswa

\begin{tabular}{ccc}
\hline No. & Rentang Presentase Hasil Motivasi Belajar & Kategori \\
\hline 1. & $80 \%-100 \%$ & Sangat baik \\
2. & $66 \%-79 \%$ & Baik \\
3. & $56 \%-65 \%$ & Cukup \\
4. & $40 \%-55 \%$ & Kurang \\
5. & $<39 \%$ & Sangat kurang \\
\hline
\end{tabular}

Rumus menghitung presentase motivasi belajar siswa adalah sebagai berikut:

Presentase motivasi $=\frac{\text { jumla } h \text { skor } \text { yang diperole } h}{\text { skor maksimum }} \times 100 \%$ 


\section{HASIL PENELITIAN DAN PEMBAHASAN}

Motivasi siswa selama pembelajaran diukur dengan menggunakan angket motivasi belajar. Angket motivasi belajar ini diberikan pada saat pretest untuk melihat motivasi awal siswa sebelum diterapkan dengan media permainan ular tangga. Kemudian angket diberikan lagi pada saat posttest untuk melihat motivasi akhir siswa sesudah diterapkan dengan media permainan ular tangga. Hasil motivasi belajar siswa diberikan pada Gambar 1.

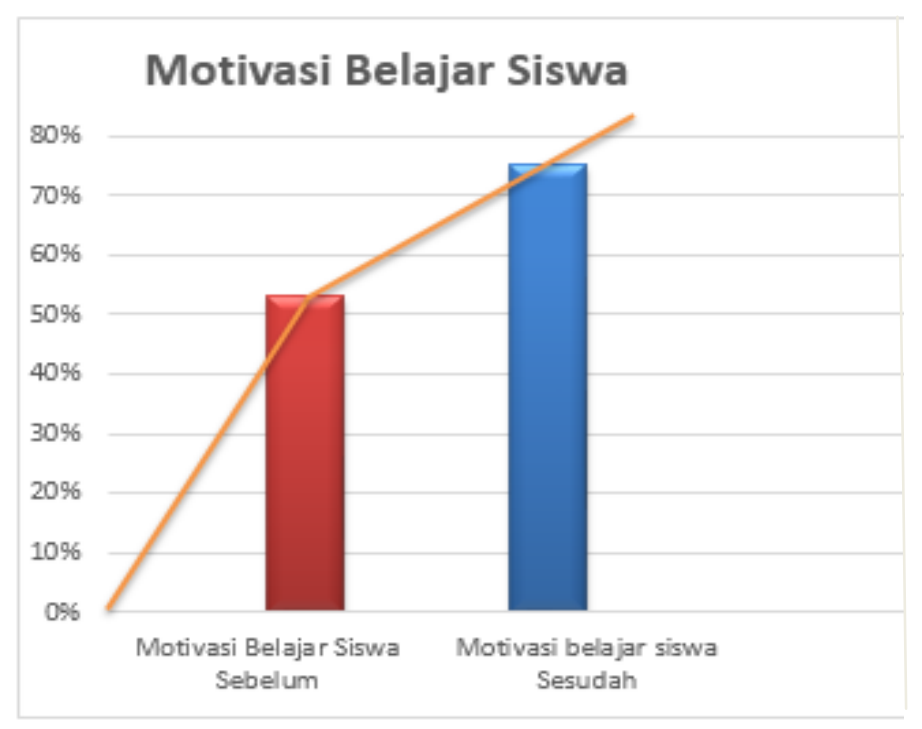

Gambar 1. Hasil Motivasi Belajar Siswa

Selama proses pembelajaran hasil motivasi belajar siswa sebelum diterapkan media permainan ular tangga sebesar 53,09\% dengan kriteria kurang dan hasil motivasi belajar siswa setelah diterapkan media permainan ular tangga sebesar $75 \%$ dengan kriteria baik. Jadi motivasi belajar siswa mengalami peningkatan.

Adapun persentase motivasi belajar yang dikelompokkan berdasarkan kategori diberikan pada Gambar 2. 


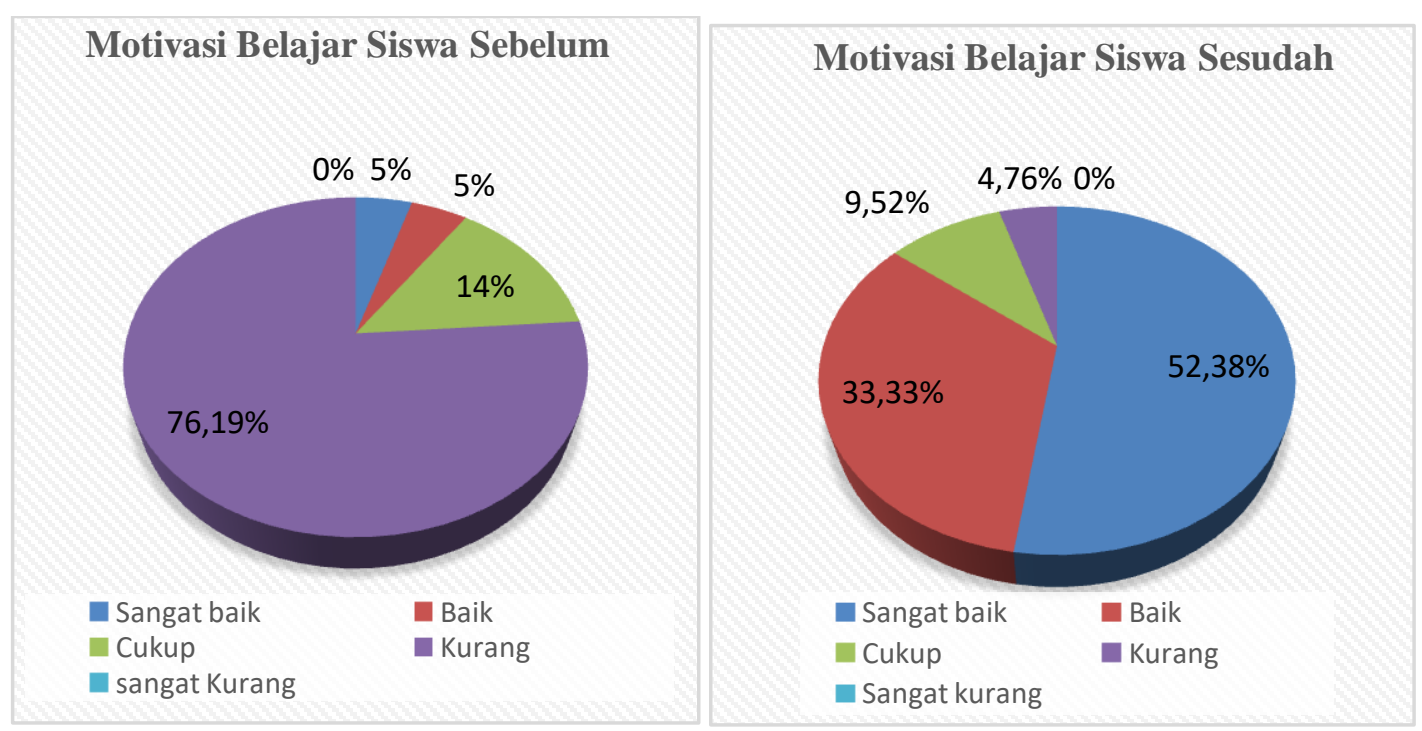

Gambar 2. Motivasi Belajar Siswa

Berdasarkan Gambar 2, motivasi belajar siswa sebelum diterapkan media permainan ular tangga menunjukkan bahwa dari 21 responden ada $4.76 \%$ dengan kategori sangat baik, ada $4.76 \%$ dengan kategori baik, ada $14.28 \%$ dengan kategori cukup, ada $76.19 \%$ dengan kategori kurang, dan ada $0 \%$ dengan kategori sangat kurang. Sedangkan motivasi belajar siswa sesudah diterakan media permainan ular tangga menunjukkan bahwa dari 21 responden ada $52.38 \%$ dengan kategori sangat baik, ada $33.33 \%$ dengan kategori baik, ada $9.52 \%$ dengan kategori cukup, ada $4.76 \%$ dengan kategori kurang, dan ada 0\% dengan kategori sangat kurang. Terdapat perubahan antara motivasi belajar siswa sebelum dan motivasi belajar siswa sesudah, sehingga dapat disimpulkan bahwa proses pembelajaran dengan menggunakan media permainan ular tangga dapat meningkatkan motivasi belajar siswa.

Sebelum dilakukan uji analisis data, maka diperlukan uji prasyarat untuk mengetahui data berdistribusi normal atau tidak. Pengujian normalitas data pada penelitian ini dilakukan dengan cara uji statistik parametrik yaitu menggunakan uji One Sample Kolmogorov Smirnov. Hasil pengujian variabel dengan menggunakan uji One Sample Kolmogorov Smirnov, menunjukkan bahwa hasil motivasi belajar siswa sebelum dan motivasi belajar sesudah mempunyai data tidak normal. Jika data tersebut berdistribusi tidak normal maka dapat ditentukan uji hipotesis yang sesuai digunakan yaitu Wilcoxon Signed Rank Test. Hasil dari 
uji Wilcoxon Signed Rank Test menunjukkan bahwa nilai Asymp. Sig 0,000< 0,05 maka dapat dinyataakan Ho ditolak, artinya ada perbedaan antara motivasi belajar siswa sebelum diterapkan media permainan ular tangga dan motivasi belajar siswa sesudah diterapkan media permainan ular tangga. Sehingga dapat disimpulkan ada pengaruh media permainan ular tangga terhadap motivasi belajar siswa.

Selama kegiatan belajar mengajar dengan menggunakan media permainan ular tangga, terlihat siswa lebih aktif, semangat, dan mereka serius mengerjakan soal yang ada dalam permainan tersebut. Dalam kegiatan belajar mengajar menggunakan media dapat menarik perhatian siswa, apalagi untuk siswa kelas II SD karakteristiknya mereka suka bermain. Salah satu upaya untuk meningkatkan motivasi belajar siswa yakni dengan menggunakan media sejalan pendapat Arsyad (2013) menyatakan bahwa pemakaian media pembelajaran dalam proses belajar mengajar dapat membangkitkan keinginan dan minat baru, membangkitkan motivasi dan membawa pengaruh-pengaruh psikologi dalam siswa. Ketika media diterapkan pada saat proses pembelajaran akan menarik perhatian siswa sehingga siswa lebih semangat dalam belajar. Sejalan dengan pendapat Sundayana (2015) menyatakan bahwa media mempunyai fungsi menimbulkan gairah belajar, interaksi lebih langsung antara siswa dengan sumber belajar.

\section{SIMPULAN}

Hasil motivasi belajar siswa sebelum diterapkan media permainan ular tangga sebesar 53,09\% dengan kriteria kurang dan hasil motivasi belajar siswa setelah diterapkan media permainan ular tangga sebesar $75 \%$ dengan kriteria baik. Jadi motivasi belajar siswa mengalami peningkatan dan ada pengaruh penggunaan media permainan ular tangga terhadap motivasi belajar siswa.

\section{DAFTAR PUSTAKA}

Arikunto, S. (2008). Prosedur Penelitian Suatu Pendekatan Praktikum. Jakarta: Bumi Aksara.

Arsyad, A. (2013). Media Pembelajaran. Jakarta: PT Raja Grafindo Persada. Iskandar. (2009). Psikologi Pendidikan Sebuah Orientasi Baru. Ciputat: Gaung Persada Press. 
Ismail, A. (2006). Education Games. Jakarta: Pilar Media.

Satrianawati. (2018). Media dan Sumber Belajar. Yogyakarta: CV Budi Utama.

Sumantri, S. (2015). Strategi Pembelajaran: Teori dan Praktik di Tingkat Pendidikan Dasar. Jakarta: PT Raja Grafindo Persada.

Sundayana, R. (2015). Media dan Alat Peraga dalam Pembelajaran Matematika. Bandung: Alfabeta.

Zulfa, N. W. (2016). Efektivitas Permainan Ular Tangga Matematika Terhadap Peningkatan Kemampuan Berhitung Siswa Kelas III MI Sultan Agung. Skripsi. UIN Sunan Kalijaga. 